\title{
Clonidine is a better test for growth hormone deficiency than insulin hypoglycaemia
}

\author{
N C FRASER, J SETH, AND N S BROWN \\ Royal Hospital for Sick Children and Immunoassay Section, Department of Clinical Chemistry, \\ Royal Infirmary of Edinburgh, Edinburgh
}

SUMMARY The oral clonidine test was compared with the standard intravenous insulin hypoglycaemia test in 41 children and adolescents with short stature. In those without growth hormone deficiency clonidine provoked a significantly higher mean plasma growth hormone response and gave fewer false subnormal responses (apparent growth hormone deficiency) than insulin. Children with psychosocial deprivation had poorer responses to both tests. In view of these findings and the absence of unacceptable side effects with clonidine it is concluded that the oral administration of this alpha-adrenergic stimulant is a safe and reliable alternative test of growth hormone release.

Among definitive tests of growth hormone (somatotropin) release $^{1}$ no single stimulus has shown greater reliability than the insulin hypoglycaemia test (IHT), which is the investigation preferred by the United Kingdom's Health Services Human Growth Hormone Committee. ${ }^{2}$ Although the IHT has the advantage of assessing the hypothalamic-pituitary-adrenal axis in addition to growth hormone (GH) secretion, there is some risk, albeit small, and alternatives have therefore been sought. Oral administration of the alpha-adrenergic drug clonidine has been shown to stimulate GH release in normal subjects ${ }^{3}$ and was tried successfully by Gil-Ad et al. ${ }^{4}$ as a test for GH deficiency. In a multicentre trial ${ }^{5}$ oral clonidine and the IHT were similarly reliable as tests for GH secretion. The purpose of the present study was to compare these two tests in a further series of patients under the more standardised conditions of a single centre.

\section{Patients and methods}

Patients. Both tests were performed on 41 patients ( 30 boys and 11 girls) with short stature (height standard deviation score $-3 \cdot 0 \pm 0 \cdot 1$, mean \pm SEM). The age range was 3.7 to 16.7 years, mean 10.4 years. Seven patients proved to be biochemically $\mathrm{GH}$ deficient and a further 6 had distinct clinical disorders affecting growth (Table). In the remaining 28 the predominant feature was a 'short/delay' pattern of growth, with bone age $-2 \cdot 1 \pm 0 \cdot 2$ years (mean \pm SEM less than chronological age). ${ }^{6}$ Other factors in these 28 patients were extreme familial short stature without maturational delay in 1 , low birthweight
Table Clinical diagnoses in 41 patients with short stature

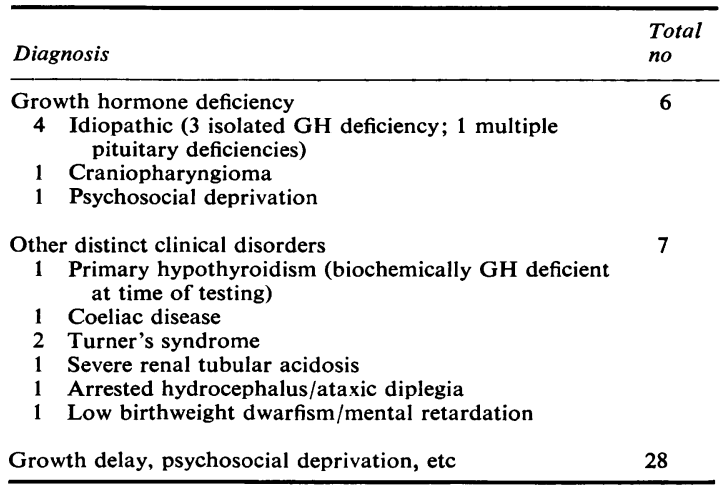

dwarfism in 2, unclassified dysmorphic features in 1 , asthma in 3 (none were on steroids when tested), and known or suspected psychosocial deprivation in 10. The results on 17 of these 41 patients are in the multicentre report. ${ }^{5}$

Test procedures. All the tests were performed with the patients resting after an overnight fast. In 21 children both tests were carried out in the same week; in 13 the tests were on consecutive days and in 9 of these the IHT was performed first. The other 20 children were tested at a median interval of 6 months. One prepubertal boy was primed with a depot injection of mixed testosterone esters in the week before having both tests. 
The clonidine test was performed as described by Gil-Ad et al. ${ }^{4}$ using an oral dose of $0.15 \mathrm{mg} / \mathrm{m}^{2}$ body surface area. Clonidine was given as Dixarit tablets, (WB Pharmaceutical Ltd) each of which contains 25 $\mu \mathrm{g}$, and the dosage was rounded up to the nearest number of tablets. Blood pressure was measured half hourly throughout the procedure, and patients were observed in the ward for a further hour before going home.

The IHT was carried out using neutral soluble insulin (Velosulin, Nordisk) in an intravenous dose of $0.15 \mathrm{U} / \mathrm{kg}$ bodyweight, except in 3 cases where panhypopituitarism was suspected, when $0.075 \mathrm{U} / \mathrm{kg}$ was given. After the IHT all patients were observed overnight. In both procedures samples for $\mathbf{G H}$ analysis were taken half hourly for $2 \frac{1}{2}$ hours through an indwelling intravenous cannula. During the IHTs an additional sample was taken 15 minutes after the insulin injection to confirm hypoglycaemia, and all samples were assayed for glucose and cortisol. In both tests a maximum $\mathrm{GH}$ concentration of $15 \mathrm{mU} / \mathrm{l}$ or greater was taken to exclude GH deficiency. ${ }^{7}$

Growth hormone assay. Plasma GH concentration was estimated by a double antibody radioimmunoassay ${ }^{8}$ modified for use with the Kemtek semiautomated radioimmunoassay system (Kemble Instruments, Burgess Hill, Sussex). The assay was calibrated in terms of the 1st International Reference Preparation of HGH (code 66/217), using as a working calibrant ampoules $(32 \mu \mathrm{U} /$ ampoule) prepared by the UK External Quality Assessment Schemes for Peptide Hormones (EQAS, Edinburgh). Assay precision (coefficient of variation) averaged $6 \%$, both within and between assay. In the UK EQAS the bias of the GH assay relative to the all-laboratory trimmed mean remained in the range $-2.3 \%$ to $6.5 \%$ (mean $+2.5 \%$ ) during the period of study.

\section{Results}

All patients. The maximum GH concentrations achieved in each patient during the two procedures are shown in Figure 1. In the IHTs adequate hypoglycaemia and cortisol responses were seen in all cases. Of the 41 pairs of tests, the results agreed in 30: 23 patients had normal responses to both tests and 7 had subnormal responses to both. The other 11 pairs of results were discordant: 2 patients had a normal response to insulin only and 9 had a normal response to clonidine only. In the other 6 patients with distinct clinical disorders 2 had normal responses to both tests, 2 to insulin only, and 2 to clonidine only.

Patients without growth hormone deficiency. The tests

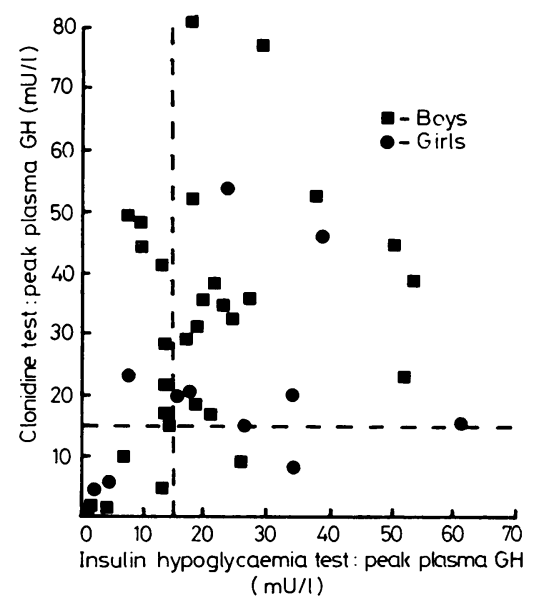

Fig. 1 Maximum plasma growth hormone responses to intravenous insulin and to oral clonidine in 41 children and adolescents.

were compared in the 28 patients remaining after excluding the 7 with GH deficiency and the 6 with other distinct clinical disorders (Table). These 28 children showed mainly growth delay and were those in whom the greatest diagnostic difficulty might have arisen. Growth hormone deficiency was excluded in 21 patients whose responses to both tests were normal. None of the 28 had a normal response to insulin only, but 7 had a normal response to clonidine only. These 7 would have been misdiagnosed by the IHT alone as having some degree of biochemical GH deficiency.

In the 28 patients the maximum $\mathrm{GH}$ value in response to insulin was (mean \pm SEM) $23 \cdot 5 \pm 2 \cdot 6$ $\mathrm{mU} / 1$ and to clonidine (mean \pm SEM) $37 \cdot 6 \pm 3 \cdot 2$ $\mathrm{mU} / \mathrm{l}$, with a mean difference between paired values of $16.4 \pm 3.6 \mathrm{mU} / 1 \quad(\mathrm{P}<0.001$, paired $t$ test $)$. Responses to clonidine were not, however, higher in all cases (Fig. 1). Figure 2 shows the mean response curves in the 28 patients. The area under the clonidine curve is 1.5 times that under the IHT curve.

Psychosocial deprivation. Of the 28 patients without GH deficiency, the 10 with known or suspected psychosocial deprivation gave poorer responses to both tests. In the IHT the maximum $\mathrm{GH}$ value for these 10 was (mean \pm SEM) $20 \cdot 4 \pm 3 \cdot 2 \mathrm{mU} / 1$, compared with $25 \cdot 2 \pm 3 \cdot 7 \mathrm{mU} / 1$ for the remaining 18 patients. The corresponding concentrations in the clonidine test were (mean \pm SEM) $31 \cdot 1 \pm 3.5 \mathrm{mU} / 1$ and $41 \cdot 2 \pm 4 \cdot 4$ respectively. The difference between the results for the psychosocially deprived patients and the remaining patients was not statistically significant for either test. 


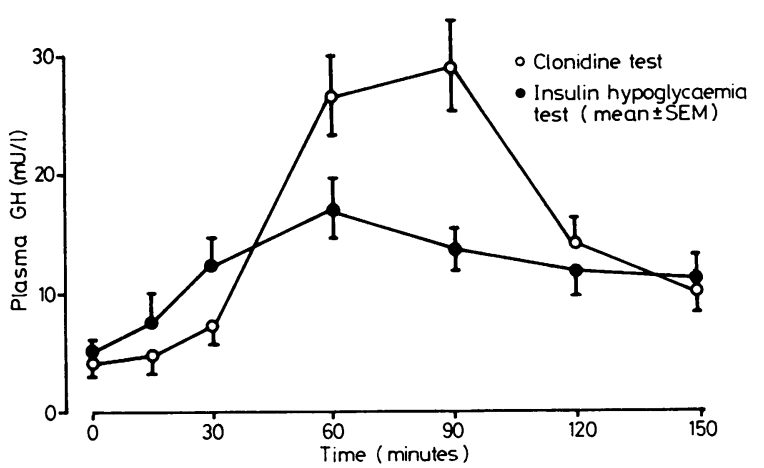

Fig. 2 Plasma growth hormone responses to intravenous insulin and to oral clonidine in 28 patients without growth hormone deficiency.
Need for repeat tests. Five patients had shown deficient responses to insulin during 7 previous IHTs. Two proved to be $\mathrm{GH}$ deficient and 2 gave satisfactory responses when retested during this survey. The fifth failed to respond to adequate hypoglycaemia on 2 occasions but achieved a normal GH response after clonidine. Five children had repeat clonidine tests: one because of a change of care associated with rapid catch up growth; a girl with Turner's syndrome responded poorly on 2 occasions; one outpatient proved not to have fasted before his first test; and in another the procedure had been started late in the morning. In 3 of the 5 with poor responses to their first clonidine test the basal GH values were raised in the range 10.6 to 14.3 $\mathrm{mU} / \mathrm{l}$. This may have been due to stress, and may have contributed to their refractoriness to stimulation, although others achieved good GH responses to clonidine in spite of such raised basal values. Where patients had more than one clonidine test or IHT the one showing the better response was used in the study.

Timing of tests. The 21 patients who had both tests performed in the same week had mean maximum responses both to insulin and clonidine within $2 \mathrm{mU} / 1$ of the mean values of the 20 whose tests were carried out some months apart.

Side effects. No child developed troublesome side effects from either procedure. After clonidine most became drowsy or slept briefly. All were able to get up within an hour of the end of the test without symptoms of hypotension. Older children volunteered that clonidine was much less unpleasant than insulin.

\section{Discussion}

The results of the many tests of $\mathrm{GH}$ secretion that have been tried suggest that none is entirely satisfactory. Physiological secretory episodes after exercise, during slow wave sleep, or 3-4 hours after a meal or oral glucose load are either not reliably produced or not conveniently detected, so that 25 to $50 \%$ of children so tested will show falsely subnormal responses, depending on the plasma value taken to indicate partial biochemical deficiency. ${ }^{1}$ It is desirable to confirm the diagnosis of $\mathbf{G H}$ deficiency before age 6 years, ${ }^{9}$ and although exercise is useful as a screening procedure it is difficult to persuade children of this age to exercise adequately for the purpose.

Definitive procedures depend on simulating one or more of the mechanisms controlling $\mathrm{GH}$ release, such as stress, hypoglycaemia, or central alphaadrenergic or dopaminergic stimulation. ${ }^{10}$ Insulin induced hypoglycaemia is as reliable as any other single stimulus but may still produce $25 \%$ false subnormal responses, even when, as in our study, the larger dose of $0.15 \mathrm{U} / \mathrm{kg}$ is given to ensure adequate hypoglycaemia (perhaps increasing the risk of a serious reaction). Some doctors prefer insulin to pharmacological agents as a natural stımulant of $\mathbf{G H}$ release, but whether the degree of hypoglycaemia achieved during the IHT is truly physiological must be questioned. Fewer false subnormal responses have been found by combining stimuli, ${ }^{11-14}$ but these procedures have disadvantages in duration, complexity and side effects..$^{15} 16$

This study extends the multicentre trial in 61 children previously reported ${ }^{5}$ since it describes the experience of a single centre with a further 24 patients (41 in all). This ensured that the test procedure ${ }^{4}$ was consistently adhered to, especially pretest fasting. In the multicentre study several children were fasted for the IHT but not for the clonidine test and so their GH responses to clonidine may have been inhibited. In addition, all GH assays in this study were performed in a single laboratory, eliminating the effects of inter-laboratory variation. Full GH responses were measured in all cases to permit better 
comparison of results, whereas in the multicentre study several responses were simply expressed as 'greater than'.

In the smaller group of 28 patients with a predominantly 'short/delay' pattern of growth and in whom GH deficiency was excluded because of an adequate $\mathrm{GH}$ response to clonidine, subnormal responses to insulin were seen in 7 . These false subnormal responses do not seem to be a consequence of a proportionally higher response to clonidine in all patients. Had this been the case, a higher GH value might have been taken as the criterion of normal response in the clonidine test. Indeed, Figure 1 shows that responses to clonidine were similar in those with and without normal responses to insulin. It seems, therefore, that clonidine can more effectively overcome any refractoriness to stimulation which may occur if the basal GH concentration is raised in the range $10-15 \mathrm{mU} / 1$. In such a case a failed response should lead to the test being repeated.

The parents of very small children are naturally protective and the publicity given to rare accidents with the IHT hinders some from consenting to an investigation, which careful clinical and auxological assessment ${ }^{2}$ has shown to be desirable. The oral clonidine test is a simple, safe alternative procedure during much of which the child is comfortably drowsy. It is unlikely that any test of GH release could give entirely consistent results, but this study shows that clonidine produces false subnormal responses less frequently than insulin and can be recommended as a definitive test of $\mathrm{GH}$ secretion.

There remains the possibility that a normal GH response to clonidine may not exclude treatable GH deficiency. Immunologically reactive GH may be biologically inert, ${ }^{17}$ or the occasional patient may respond to pharmacological stimulation but fail to release $\mathrm{GH}$ physiologically. ${ }^{18}$ It has been suggested that children with psychosocial growth retardation may fall into this last category. ${ }^{19}$ Psychosocially deprived children in this series showed reduced, but not significant mean responses both to insulin and to clonidine. The ultimate proof of GH deficiency is in the patient's response to replacement therapy.

We thank Professor J W Farquhar for his comments and for permission to study his patients.

\section{References}

1 Frasier S D. Growth hormone stimulation tests in children. In: Raiti S, ed. Advances in human growth hormone research. Publication No (NIH) 74-612. Washington: DHEW, $1973 ; 632-57$.

2 Milner R D G, Burns E C. Investigation of suspected growth hormone deficiency. Arch Dis Child 1982; 57: 944-7.
${ }^{3}$ Lal S, Tolis G, Martin J B, Brown G M, Guyda H. Effect of clonidine on growth hormone, prolactin luteinizing hormone, follicle-stimulating hormone, and thyroidstimulating hormone in the serum of normal men. $J$ Clin Endocrinol Metab 1975; 41: 827-32.

4 Gil-Ad I, Topper E, Laron Z. Oral clonidine as a growth hormone stimulation test. Lancet 1979 ; ii: $278-80$.

5 Health Services Human Growth Hormone Committee. Comparison of the intravenous insulin and oral clonidine tolerance tests for growth hormone secretion. Arch Dis Child 1981; 56: 852-4.

6 Tanner J M, Whitehouse $\mathrm{R}$ H, Marshall W A, et al. Assessment of skeletal maturity and prediction of adult height (TW2 method). London: Academic Press, 1975.

7 Preece M A. Diagnosis and treatment of children with growth hormone deficiency. Clin Endocrinol Metab 1982; 11: 1-24.

8 Hunter W M. Radioimmunoassay of growth hormone (HGH, somatotropin, STH) in plasma. In: Bruer $\mathrm{H}$, Hamel D, Kruskemper $\mathrm{H} \mathrm{C}$, eds. Methods of hormone analysis. Stuttgart: Thieme, 1976:1-11.

9 Tanner J M. Towards complete success in the treatment of growth hormone deficiency: a plea for earlier ascertainment. Health Trends 1975; 7: 61-5.

10 Root A W. Regulation of secretion of human growth hormone. In: La Cauza C, Root A W, eds. Problems in pediatric endocrinology. Proceedings of the Serono Symposia. Vol. 32. London: Academic Press, 1980: 3-20.

11 Collu R, Leboeuf G, Letarte J, Ducharme J R. Stimulation of growth hormone secretion by levodopapropranolol in children and adolescents. Pediatrics 1975; 56: $262-6$.

12 Weldon V V, Gupta S K, Klingensmith G, et al. Evaluation of growth hormone release in children using arginine and L-Dopa in combination. J Pediatr 1975; 87: $540-4$.

13 Shanis B S, Moshang T, Jr. Propranolol and exercise as a screening test for growth hormone deficiency. Pediatrics 1976; 57: 712-4.

14 Fass B, Lippe B M, Kaplan S A. Relative usefulness of three growth hormone stimulation screening tests. $\mathrm{Am} \mathrm{J}$ Dis Child 1979; 133: 931-3.

15 LaFranchi S H, Lippe B M, Kaplan S A. Hypoglycemia during testing for growth hormone deficiency. $J$ Pediatr 1977; 90: 244-5.

16 Rowe D W, Sare Z, Kelley V C. Letter: Possible complications of the levodopa-propranolol test. Pediatrics 1977; 60: $132-3$.

17 Rudman D, Kutner M H, Blackston R D, Cushman R A, Bain R P, Patterson J H. Children with normal variant short stature: treatment with human growth hormone for six months. $N$ Engl J Med 1981; 305: 123-31.

18 Collu R, Brun G, Milsant F, Leboeuf G, Letarte J, Ducharme J R. Re-evaluation of levodopa-propranolol as a test of growth hormone reserve in children. Pediatrics $1978 ; 61: 242-4$.

19 Howse P M, Rayner P H W, Williams J W, et al. Nyctohemeral secretion of growth hormone in normal children of short stature and in children with hypopituitarism and intrauterine growth retardation. Clin Endocrinol $(O x f)$ 1977; 6: 347-59.

Correspondence to Dr N C Fraser, Royal Hospital for Sick Children, Sciennes Road, Edinburgh EH9 $1 \mathrm{LF}$.

Received 20 January 1983 